\title{
Landscape resistance influences effective dispersal of endangered golden lion tamarins within the Atlantic Forest
}

\author{
Andreia Magro Moraes ${ }^{\mathrm{a}, \mathrm{b}, \mathrm{c}, *}$, Carlos R. Ruiz-Miranda ${ }^{\mathrm{a}}$, Pedro M. Galetti Jr. ${ }^{\mathrm{b}}$, \\ Bernardo Brandão Niebuhr ${ }^{\mathrm{c}}$, Brenda R. Alexandre ${ }^{\mathrm{d}}$, Renata L. Muylaert ${ }^{\mathrm{c}}$, Adriana D. Grativol ${ }^{\mathrm{a}}$, \\ John W. Ribeiro ${ }^{c}$, Arystene N. Ferreira ${ }^{b}$, Milton Cezar Ribeiro ${ }^{c}$ \\ a Programa de Pós-graduação em Ecologia e Recursos Naturais, Instituto de Biociências e Biotecnologia, Universidade Estadual do Norte Fluminense, 28013-602 Campos \\ dos Goytacazes, RJ, Brazil \\ ${ }^{\mathrm{b}}$ Laboratório de Biodiversidade Molecular e Conservação, Departamento de Genética e Evolução, Universidade Federal de São Carlos, 13565-905 São Carlos, SP, Brazil \\ ${ }^{\mathrm{c}}$ Laboratório de Ecologia Espacial e Conservação (LEEC), Instituto de Biociências, Universidade Estadual Paulista (UNESP), 13506-900 Rio Claro, SP, Brazil \\ d Programa de Pós-graduação em Ecologia, Departamento de Ecologia, Instituto de Biologia, Universidade Federal do Rio de Janeiro, 21941-590 Rio de Janeiro, RJ, Brazil
}

\section{A R T I C L E I N F O}

\section{Keywords:}

Individual-based analyses

Isolation by resistance

Landscape genetics

Primate conservation

Sex-biased dispersal

\begin{abstract}
A B S T R A C T
Habitat fragmentation threatens tropical rainforests, which can significantly hinder dispersal in species such as arboreal primates. For conservation actions to be effective there must be an understanding of how landscape structure and biological traits shape dispersal. We assessed the effects of landscape, sex and population management (reintroductions and translocations) on gene flow of Leontopithecus rosalia, an endangered arboreal primate living in highly fragmented forests of Brazil. We genotyped 201 individuals using 14 microsatellite loci to answer three questions: (1) How far does L. rosalia disperse? (2) Is dispersal sex-biased? (3) What are the relative contributions of population management, distance, roads and landscape resistance to genetic kinship? We hypothesized that (1) gene flow decrease between more distant sites; (2) males disperse more than females; and (3) management and land-cover resistance (i.e. landscape resistance) are the variables that most influence genetic kinship. We found positive spatial population-structure up to $8 \mathrm{~km}$. The spatial structure was similar between females and males suggesting that they equally contribute to gene flow. Management and landscape resistance best explained genetic kinship, showing that different land-cover types affect the dispersal at different degrees of landscape permeability. We advocate that maintaining more permeable landscapes is essential to ensure dispersal and gene flow of arboreal mammals. Conservation measures in tropical rainforests must take into account not only the habitat amount, but also the degree at which each land use - roads, urban areas, agriculture, pasture, isolated trees, and stepping stones - facilitates or impedes the species dispersal.
\end{abstract}

\section{Introduction}

Dispersal is among the main factors influencing population dynamics and viability. It is directly affected by landscape changes, particularly those associated to habitat fragmentation (e.g. inter-habitat distance, matrix composition and the presence of barriers), and by intrinsic characteristics of organisms such as sex, vagility through various land-cover types and dispersal strategies (Henriques-Silva et al., 2015; Nathan, 2008). The interplay of these external and organismal factors determines landscape connectivity: the capacity of landscapes to promote or impede animal movements (Arroyo-Rodríguez and Mandujano, 2009; Henriques-Silva et al., 2015; Nathan, 2008; Taylor et al., 1993). In fragmented landscapes, genetic connectivity may not be significantly hindered in species with high dispersal capacity - e.g. Pardalotus striatus and Lichenostomus penicillatus (Amos et al., 2012, 2014), Procyon lotor (Dharmarajan et al., 2014), and Puma concolor (Castilho et al., 2011) whereas populations of less mobile species that rely on tree cover to move may become genetically differentiated - e.g. Malurus cyaeneus and Lichenostomus melanops (Amos et al., 2012, 2014), and Mintonius gloydi (Row et al., 2010).

Arboreal primates are an example of animals whose dispersal is sensitive to forest connectivity (Arroyo-Rodríguez and Mandujano, 2009) and are threatened with extinction due to habitat fragmentation, particularly in the Neotropics (Estrada et al., 2017). However, few studies have investigated how primate dispersal is affected by distinct landscape attributes such as distance (e.g. Mandujano et al., 2004; Mickelberg, 2011), roads (e.g. Teixeira et al., 2013) and the structure of inter-habitat matrix (e.g. Pozo-Montuy et al., 2011; Silva et al., 2015).

\footnotetext{
* Corresponding author.

E-mail address: andreia_magro@hotmail.com (A.M. Moraes).
} 
Even landscape genetics studies investigating how human-modified landscapes affect the gene flow of arboreal primates under threat of extinction are rare in the literature (e.g. Blair and Melnick, 2012; Hagell et al., 2013). These studies are important because they enable the identification of landscape attributes that affect the behavior, survival and reproduction of species, and thus may facilitate the planning of conservation actions (Sork and Waits, 2010).

The golden lion tamarin (GLT), Leontopithecus rosalia, is an arboreal primate endangered mainly by habitat fragmentation. Conservation efforts have changed its IUCN threat status from 'critically endangered' to 'endangered' (Kierulff et al., 2008). Among the conservation measures implemented are reintroduction of captive-born individuals, translocation of isolated social groups to a continuous forest, and managing the species as a metapopulation (Kierulff et al., 2012; RuizMiranda et al., 2010). A major current conservation challenge is that the region GLT inhabit - where animals were reintroduced and translocated - is highly fragmented. The low landscape connectivity and reduced gene flow may be the main threats to the long-term viability of their populations (Grativol et al., 2001). However, how or if the GLT disperse through human-modified landscapes is yet to be understood.

The extensive research on lion tamarins has focused mainly on within-fragment movements (e.g. Baker and Dietz, 1996; Dietz et al., 1997; Raboy and Dietz, 2004). Current knowledge of dispersal through the non-forest matrix is limited (e.g. Coelho, 2009; Dietz et al., 1997) and we lack information on how the modification of their habitat interferes in the behavior and strategies of dispersal. For example, sexrelated dispersal strategies can be different in fragmented and continuous landscapes (e.g. Alouatta caraya; Oklander et al., 2010; Leontopithecus rosalia; Paula, 2013).

Golden lion tamarins also offer a great opportunity to evaluate the effects of landscape modifications on dispersal, because there has been an extensive collection of genetic samples at different spatial and temporal scales. Furthermore, since the founding of the reintroduced and translocated GLT populations (from 1983; Kierulff et al., 2012), the landscape where these populations occur remains relatively stable with little reduction in the forest cover $(<3 \%$; Seabra, 2012). These small temporal changes reduce the probability of confounding the effects of historic landscape and current landscape on gene flow (Hall and Beissinger, 2014). The GLT conservation project also allows for the opportunity to evaluate the influence of population management on population genetic structure in landscape genetic studies (Moraes et al., 2017).

We used molecular tools to quantify the influence of landscape patterns on effective dispersal of endangered golden lion tamarin species. Genetic variability was accessed for different GLT populations distributed throughout their current range in southeastern Brazil. We asked three main questions (Fig. 1): (1) How far do GLT individuals disperse? (2) Are female dispersers more affected by landscape changes than male dispersers? (3) What are the relative contributions of population management, distance, roads (physical barriers) and landscape resistance to GLT genetic kinship? We hypothesized that:

(1) Genetic kinship decreases with the distance between sites. This differentiation pattern is referred to as isolation by distance (Slatkin, 1985);

(2) The negative correlation between genetic kinship and distance between sites is more pronounced in females than in males. Field studies suggest a sex-bias on the frequency of dispersal (Baker and Dietz, 1996);

(3) Genetic kinship will be higher for animals within the same type of managed population (native or unmanaged, reintroduced and translocated). This is a result of management strategy: tamarins were translocated and reintroduced into separate areas devoid of wild tamarins (Kierulff et al., 2012);

(4) Genetic kinship will be negatively correlated with distance, road presence, and landscape resistance; the influence of these factors will follow the order (from highest to lowest): population management, landscape resistance, roads and distance.

\section{Material and methods}

\subsection{Study area and genetic data sampling}

The study was conducted at São João River Basin (SJRB) and the União Biological Reserve (REBIO-União) region, located in southeastern Brazil, within the highly fragmented Atlantic Forest (Ribeiro et al., 2009). To ensure that the extent of the study area was large enough to evaluate the landscape influences on GLT populations (Anderson et al., 2010), we also analyzed a 5-km buffer beyond the boundaries of the area where the species occurs (Fig. 2). This size is based on a study that reported the maximum distance dispersed by GLT to be around $6 \mathrm{~km}$ (Mickelberg, 2011). The highway BR-101 cross the SJRB from west to east, dividing the GLT distribution region into two portions, and threatening species maintenance. The average linear distance between the habitat fragments above the BR-101 highway is $158 \mathrm{~m}$ and below this distance is $300 \mathrm{~m}$. The BR-101 divide the landscape into to portions: (a) the northern portion comprises the most preserved area, with higher amounts of forest cover and less fragment isolation (Procópiode-Oliveira et al., 2008); (b) the southern portion, where the Poço das Antas Biological Reserve (PDA) and other large and isolated populations of GLT occur (e.g. VR, Fig. 2).

We selected social groups from all of the management units (MU) in the SJRB and REBIO-União designated as REBIO-União, AVI, AVII, Imbaú and Serra (above BR-101) and PDA, VR and BE (below BR-101) (Fig. 2). The MUs are units established by the Golden Lion Tamarin Association (AMLD; Associação Mico-Leão-Dourado) and collaborating researchers, whose goal is to support the GLT management (Holst et al., 2006; Mickelberg, 2011). PDA and REBIO-União consist of public protected forests, while the MUs of AVI, AVII, Imbaú, Serra, BE and RV consist of forest fragments inside private areas. Descendants of the genetically unmanaged population (referred to as native individuals) are mainly distributed within the PDA and Serra. Descendants of the captive-born animals $(\mathrm{N}=146)$ reintroduced to the wild in the period from 1984 to 2000 (referred to as reintroduced individuals) are mainly distributed within the AVI, AVII, Imbaú, RV, and BE. REBIO-União contains the descendants from six social groups that originated from four forest fragments on the coast of Rio de Janeiro State until the 90s, and that were translocated to REBIO-União in the period from 1994 to 1997 (referred to as translocated individuals) (Kierulff et al., 2012; Ruiz-Miranda et al., 2010).

Following a landscape genetics approach (Storfer et al., 2007), we simulated multi-path ecological corridors using the LSCorridors package (Ribeiro et al., 2017) to assist the choice of sampling locations of the social groups - more information on LSCorridors can be obtained at https://github.com/LEEClab/LS_CORRIDORS. As a result, we selected 48 social groups that had a minimum of two sampled individuals and covered various ranges of corridor costs - this step is best-described below in Spatial analysis section. In total, we sampled a mean of 4 $(\mathrm{SD}=2.7)$ GLT individuals per social group captured in the study area during the period 2007-2009 (hereafter referred to as 'recent'). Of a total of 201 individuals sampled in the recent period, 152 were the same used in Moraes et al. (2017). Hair samples were collected by AMLD field team and were stored in silica gel until further genetic analysis. Capture procedures are described in detail elsewhere (Dietz et al., 1994). For each sampled individual with occurrence known in 2009, we obtained information about individual identification, sex, and social group based on field records from that year. Of those animals, only the adult individuals (aged $>2$ years) were selected to reduce the influence of related individuals on the results - offspring tend to disperse out of the natal groups around two years of aged (Paula, 2013). We also analyzed the genotypes of GLTs living in the SJRB and REBIOUnião in the period 1996-1997 (hereafter referred to as 'historic') - 78 

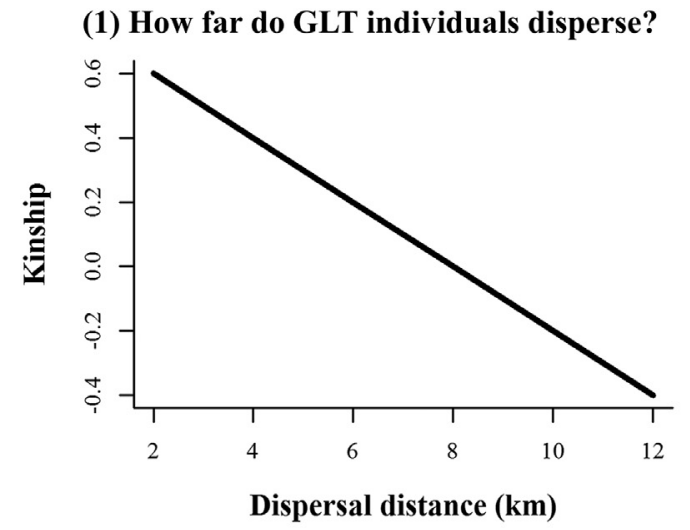

(2) Do females disperse less than males?

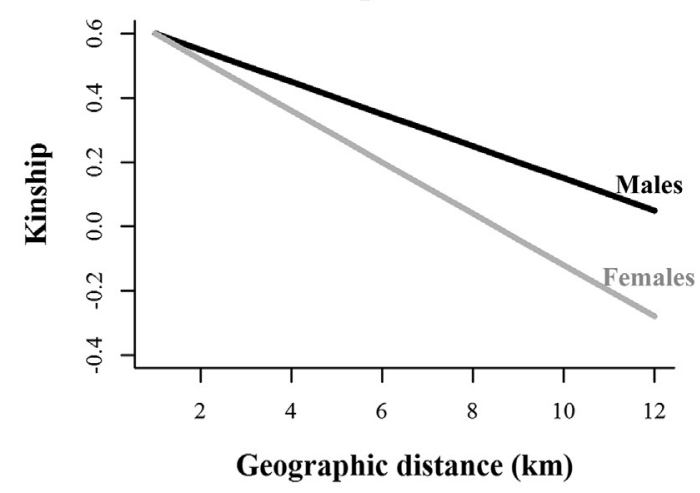

(3) What are the relative contributions of management, distance, roads and landscape resistance?

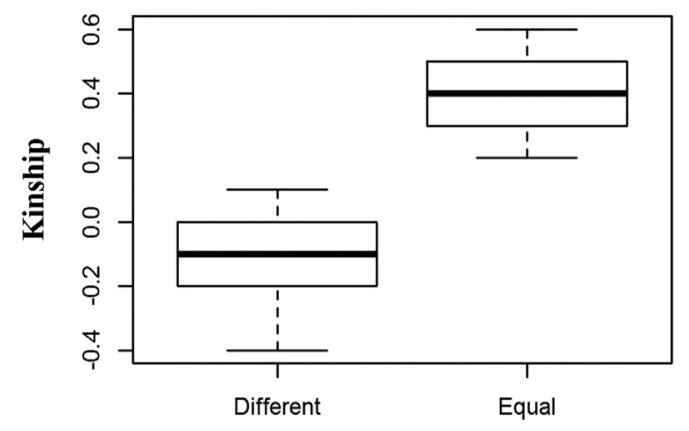

Management category

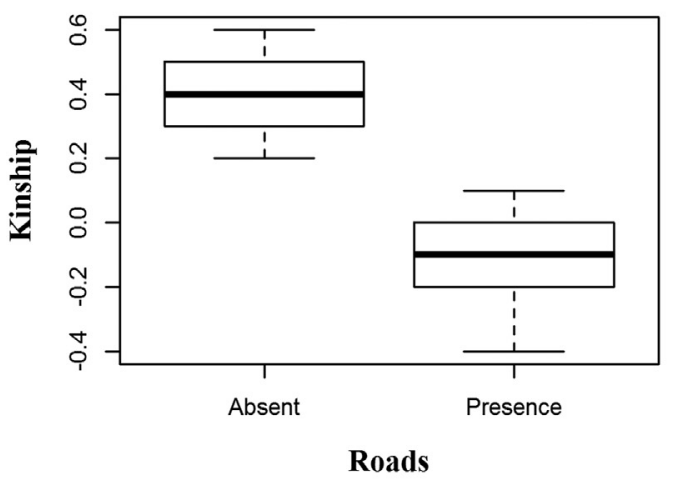

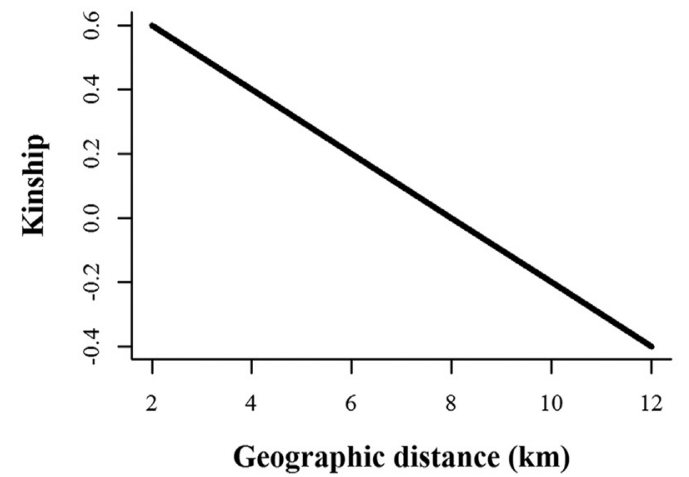

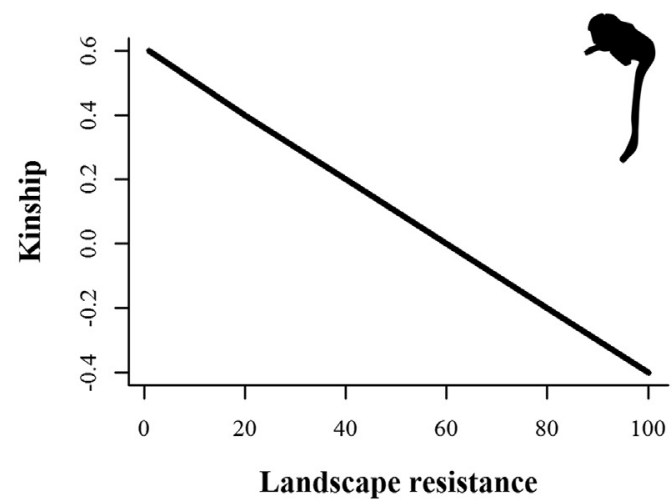

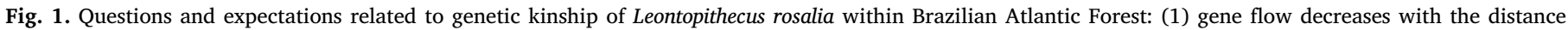

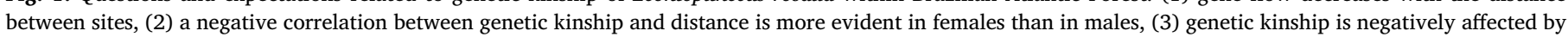

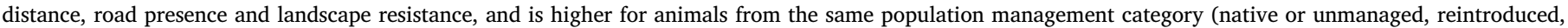
translocated, and unknown origin).

individuals from 19 social groups; data used from Moraes et al. (2017) to analyze the dispersal distances (see below). Social groups sampled are indicated in Fig. 2.

\subsection{Genetic analysis}

DNA was extracted using DNeasy Blood and Tissue Kits (Qiagen, Valencia, CA, USA) and the manufacturer's protocol. Individual genotypes were amplified from 14 microsatellite loci developed for L. rosalia (P2BH6 and P5BE6; Grativol et al., 2001), L. chrysopygus (Lchu 3, 4, 6, 7, 8 and 9; Perez-Sweeney et al., 2005) and L. chrysomelas (Leon 2, 3, 21, 27, 30 and 31; Galbusera and Gillemot, 2008). The amplified protocols and PCR conditions are also detailed in Moraes et al. (2017). For samples with missing loci, we amplified additional PCR replicates. When an individual sample was missing $>30 \%$ of the loci, the individual was removed from the analysis. To estimate the genotyping error rate and confirm reliability, we re-amplified 20 (10\%) randomly chosen samples from each locus. We estimated the error rate as the ratio between the observed number of allelic differences and the total number of allelic comparisons (Bonin et al., 2004).

We estimated an individual-based kinship parameter; this is recommended over assignment tests, which perform relatively poorly when the genetic structure is weak (Jones and Wang, 2012). Considering the population as a whole, we would have obtained a weak genetic signal because of the genetic population management of GLT that occurred on a short time scale (Moraes et al., 2017). Also, an 


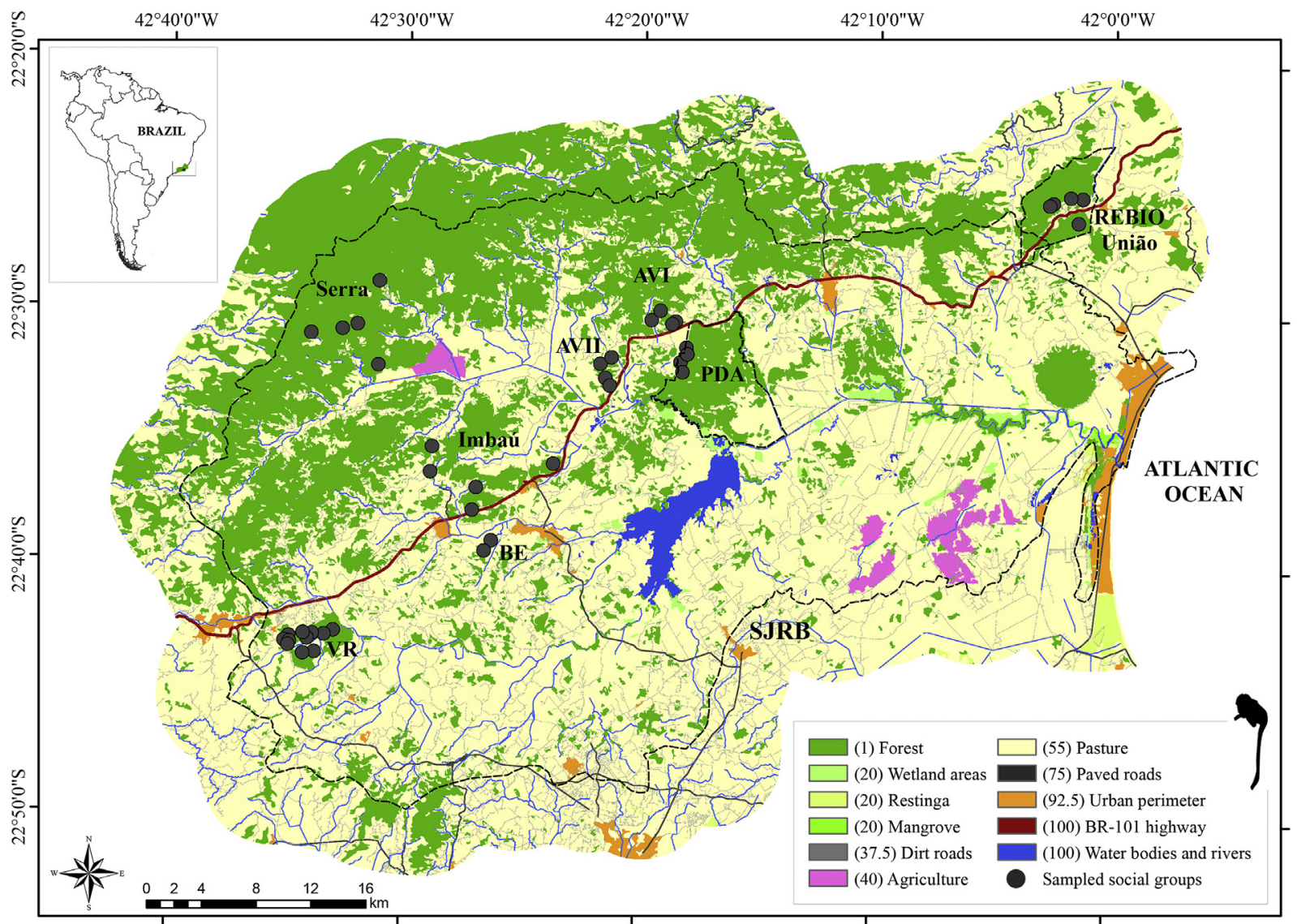

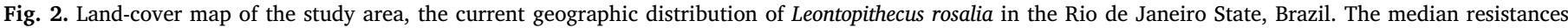

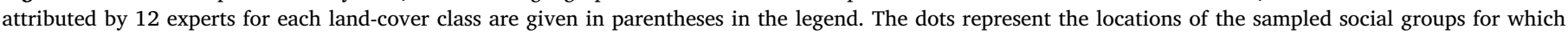
corridors were simulated.

individual-based approach may be better than population-based because it avoids the need to assign individuals to a population structure that may not be true (Shirk et al., 2010). Thus, we computed the kinship coefficients between individuals, $F_{i j}$ (Loiselle et al., 1995), using SPAGeDi (Hardy and Vekemans, 2002). We chose this particular kinship coefficient because it is indicated for non-equilibrium populations and for datasets with low-frequency alleles, and it is independent of mating systems (Vekemans and Hardy, 2004). Thus, we expected to find that landscape barriers negatively influence genetic kinship (e.g. Soare et al., 2014; Zalewski et al., 2009). Isolation by distance patterns estimated using inter-individual genetic measures may be nonlinear with distance when mating and dispersal distances are limited. To correctly account for isolation by distance effects between individuals, we also considered the mating system and dispersal patterns of GLTs (Graves, 2012).

\subsection{Spatial analysis}

We attributed resistance values to each pixel of land-cover in the study area, using GRASS GIS 7.0.3 (Neteler et al., 2012). Resistance map was built through the opinion of 12 experts who had developed studies with lion tamarins from five to 30 years. In addition, we also considered the influence of altitude on GLT movement, as it is expected that the occurrence probability of the species decreases drastically above 550 m.a.s.l. (Kierulff and Rylands, 2003). Then, we used the location of GLT social groups as source-target maps to simulate multiple path ecological corridors using LSCorridors (Fig. 2). The procedures to generate land-cover, resistance and source-target maps are available in the Supplementary material (Text A1).

After generating resistance and source-target maps, we simulated 100 corridor replicates through LSCorridors for each pair of locations of social groups. The package simulates multiple corridor routes between pairs of sources and targets allowing for individual variability on space use and movement. We used the MP (Measures by Pixel) method, which considers no influence of neighbor pixels of a given position resistance when generating the multiple paths; variability parameter was set to 2 (Ribeiro et al., 2017). After simulating the corridors for all pairs of sites, we calculated the following landscape metrics from corridor outputs: (1) Euclidean Distance (ED) - straight-line distance (given in $\mathrm{km}$ ) that separates two individuals; (2) Resistance-based Distance (RD) - effective distance (given in $\mathrm{km}$ ) between two individuals assuming that GLTs prefer to move along the most permeable paths; (3) Landscape Resistance (LR) - referred to the isolation by resistance, was calculated as the sum of the costs of crossing each pixel of the simulated corridors; and (4) Landscape Connectivity (LC = ED / LR) (Adriaensen et al., 2003; McRae, 2006; Santos, 2014; Spear et al., 2010). RD, LR and LC were calculated for each corridor and averaged over all corridors to generate a single value for each pair of individual locations. Finally, we created a binary matrix as a measurement of the presence or absence of paved roads on the route between two individual locations to test the isolation by barriers apart from the isolation by resistance. In this binary matrix, the type of road was not considered.

\subsection{Influence of sex, population management and landscape on genetic variation}

We used ED and RD to build distributions of dispersal distances of the GLT. The alleles obtained for the historic and recent periods were plotted on the land-cover map according to the geographic coordinates of the social groups. The distance between locations where the same alleles were found in the recent and historic periods was used to 
estimate the Euclidean Distance of dispersal (Fig. A1). Resistance-based Distances of dispersal were calculated as the average RD of multi-path corridors simulated with historic locations as sources and recent locations as targets. These analyses were performed in R 3.3.0 ( $\mathrm{R}$ Core Team, 2016) using the raster (Hijmans et al., 2016) and rgdal packages (Bivand et al., 2016).

All subsequent analyses were individual-based and performed using only the set of samples from the recent period. To investigate the influence of sex on potential dispersal, we tested the relationship between the pairwise kinship coefficient $\left(F_{i j}\right)$ with $\mathrm{ED}$ and $\mathrm{RD}$, for all individuals (global analyses). These analyses were also made independently for males and females. $F_{i j}$ averages were calculated for 15 distance classes, which varied from zero to $66 \mathrm{~km}$ when using ED, and from zero to $91 \mathrm{~km}$ when using RD. For individuals belonging to the same social group, we modified each of their geographic coordinates by $1 \mathrm{~m}$ so that permutations were performed using the location of all individuals. The multilocus statistical averages and two-tailed $P$ values were obtained using the jackknife estimator and 9999 permutations. To determine which predictor of ED and RD had the most influence on the genetic kinship between (1) all individuals, (2) only females and (3) only males, the regressions were carried out using three spatial extent intervals $(0-2 \mathrm{~km}, 0-6 \mathrm{~km}$, and $0-10 \mathrm{~km})$. Thus, slope $(b)$, significance level $(P$, two-tailed), and coefficient of determination $\left(r^{2}\right)$ were calculated for the 18 models. All these analyses were performed in the SPAGeDi package.

We tested for spatial autocorrelation using all the loci and then excluding separately each of the three loci with the highest percentage of missing data: Leon3, Lchu9 e Lchu7. This was done because the autocorrelation tests based on individuals did not consider the presence of missing data in the analyses (Hardy and Vekemans, 2002). We observed differences in the significance tests only when we excluded Leon3. The number of pairwise comparisons and the proportion of individuals in each distance class were represented as suggested by the software authors. The coefficient of variation of the number of times each individual was represented varied between 0.5 and 1.5.

To quantify the effects of landscape patterns on genetic kinship, we used generalized linear models (GLM) with Gaussian distribution for the response variable, $F_{i j}$. Because the population management influences GLT genetic structuring (Moraes et al., 2017), we also tested their effects on $F_{i j}$ variable. We considered the following four population management categories (Management) for individuals: (1) native, (2) reintroduced, (3) translocated, and (4) origin unknown by researchers. For each pair of individuals, we attributed a numeric code that refers to the population management categories of both individuals. After this step, we tested for the influence of the landscape variables (ED, RD, LR, LC, and Road Presence) on genetic kinship. First, we applied Spearman's correlation ( $r$ ) to check if there were high correlations between the explanatory variables. A pair of variables was considered highly correlated when the correlation coefficient was higher than 0.7 (Fig. A2) (Zurr et al., 2009). To choose one of each pair of correlated variables, we performed variable selection using Akaike's information criterion (AIC; Akaike, 1974) and kept variables with the lowest AIC among the univariate GLMs containing correlated predictors (Burnham and Anderson, 2002). At the end, four explanatory variables were used in the GLMs: Management, ED, LR and Road Presence.

We then fitted univariate and multivariate GLMs; each multivariate model included the additive effects of Management, the most significant explanatory variable among the univariate models, and a landscape variable. We also included a null model that represents the absence of effect (the intercept-only model) on the competing model list. At the end, we compared the eight competing models explaining the genetic variation: (1) Management; (2) Euclidean Distance (ED), (3) Road Presence, (4) Landscape Resistance (LR), (5) ED + Management, (6) Road + Management, (7) LR + Management, and (8) Null model. The explanatory power of each model was compared by AIC model selection and the most plausible model was identified using the evidence weight (wAIC). Evidence weight represents the relative probability of a model in comparison to the other models in the set (Burnham and Anderson, 2002). Analyses were performed with R 3.3.0, and the input data and $\mathrm{R}$ codes are available at https://github.com/ LEEClab/Landscape_genetics_GoldenLionTamarins.

\section{Results}

\subsection{Quality of genetic data}

We compared 560 alleles to investigate genotyping errors. From these, 28 alleles (from two individuals) were excluded because they could not be typed for double amplification, and another 26 alleles were typed for only one of the two extracts. We found no allelic dropout, false alleles or contaminations among the 16 amplified and checked genotypes. Only $4 \%$ of alleles were missing data, and microsatellite polymorphism ranged from three to nine alleles per locus.

\subsection{Assessing dispersal potential distances using genetic variation}

The number of shared alleles over time was negatively correlated with both Euclidean Distance (ED) and Resistance-based Distance (RD). Euclidean Distance measured between points of allele presence over time showed a median allele dispersal of $0.89 \mathrm{~km}$ (percentiles $5 \%$ and $95 \%=0-13.4 \mathrm{~km}$ ), while the median value was 2.32 higher when considering resistance-based dispersal distances (median [percentiles $5-95 \%]=2.05[0.74-23.4] \mathrm{km}$ ). For both ED and RD, the distance of allele dispersal rarely exceeded $8 \mathrm{~km}$ (Fig. A3). Global autocorrelation analyses also showed that $F_{i j}$ decreased as RD and ED increased between individuals' locations (Fig. 3). However, the distance at which $F_{i j}$ values are significantly higher than random permutation values were greater when considering RD (up to $\mathrm{RD}=7.9 \mathrm{~km}, F_{i j}=0.037, P<0.001$ ) than when considering $\mathrm{ED}$ (up to $\mathrm{ED}=4.8 \mathrm{~km}, \quad F_{i j}=0.017$, $P<0.001$ ). The $F_{i j}$ values also varied between slightly significant and no significant in $11-21 \mathrm{~km}$ for ED (Fig. 3a) and $17-31 \mathrm{~km}$ for RD (Fig. 3d). When excluding the loci with the greatest proportion of missing data (Leon3, 15\%), the pattern of variation in $F_{i j}$ remained the same, though significantly different than random permutation values in all distance classes except the fourth interval of ED $(11 \mathrm{~km})$. Thus, we found significantly lower values, especially after $24 \mathrm{~km}$ (and after $15.5 \mathrm{~km}$ excluding Leon3) considering ED and after $31 \mathrm{~km}$ (and after $17 \mathrm{~km}$ excluding Leon3) considering RD (Fig. 3).

\subsection{Evaluating sex-biased dispersal}

We observed a similar pattern in the spatial genetic structure between females and males (Fig. 3); although the coefficient of determination between the $F_{i j}$ and the distance was greater for males than for females in the first distance classes (Table 1). For females, we found a positive spatial structure up to an average ED of $5.6 \mathrm{~km}\left(F_{i j}=0.028\right.$, $P<0.001$, Fig. $3 \mathrm{~b})$ and up to an average RD of $8.7 \mathrm{~km}\left(F_{i j}=0.027\right.$, $P<0.001$, Fig. 3e). For males, we found positive spatial structuring up to an average ED of $9.2 \mathrm{~km}\left(F_{i j}=0.011, P=0.04\right.$, Fig. 3c $)$ and up to an average RD of $8.1 \mathrm{~km}\left(F_{i j}=0.026, P<0.001\right.$, Fig. 3f). For both sexes, the determination coefficient between $F_{i j}$ and distance was generally higher for RD than ED (Table 1).

\subsection{Relative contributions of population management and landscape on genetic variation}

As expected, genetic kinship was lower between individuals under different population management categories and Management was selected as the most parsimonious univariate model for the pairwise kinship genetics ( $\triangle$ AIC between population management model and the other univariate models was much higher than 2 - see Table A1). When considering population management and spatial variables, the most 

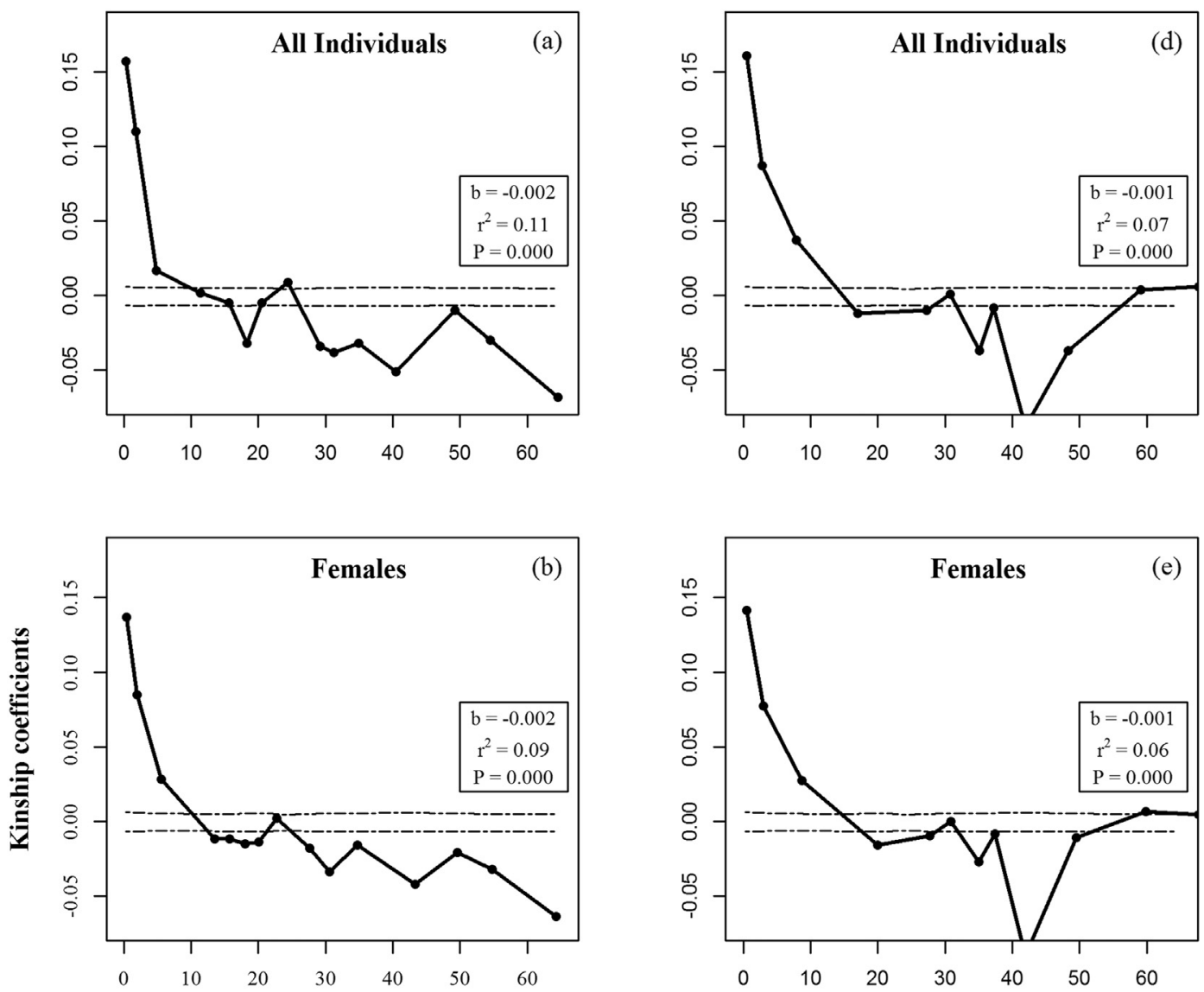

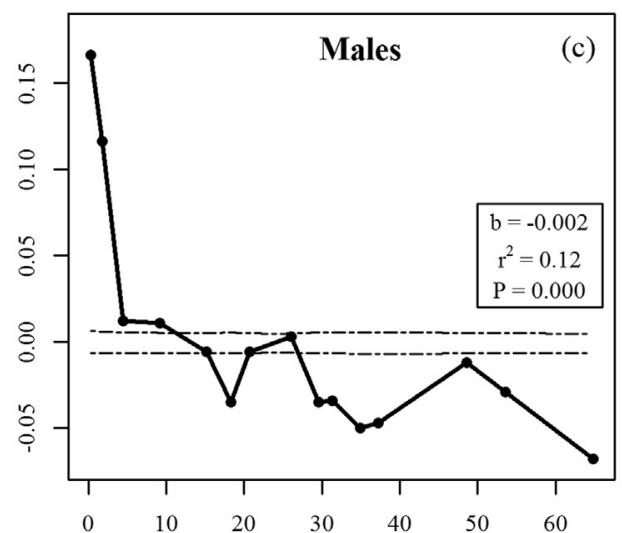

Euclidean Distance (km)

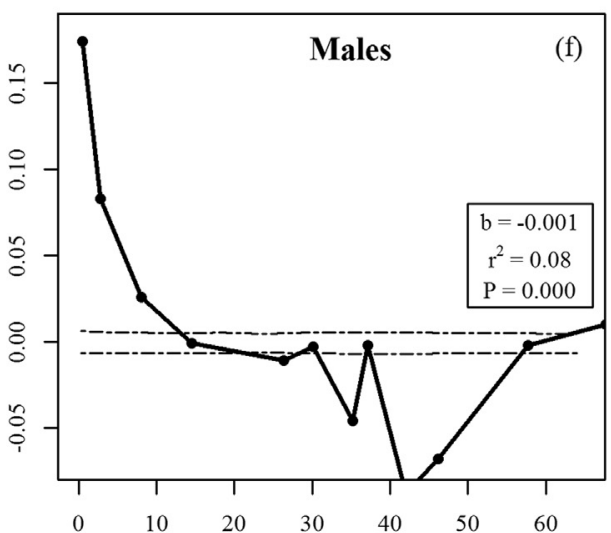

Resistance-based Distance (km)

Fig. 3. Correlograms of kinship coefficients ( $F_{i j}$, Loiselle et al., 1995) between 201 total individuals (first line), 91 females (second line) and 109 males (third line) of Leontopithecus rosalia, across 15 mean distance intervals in the São João River Basin and REBIO-União, Rio de Janeiro State, Brazil. The upper and lower 95\% confidence levels are given for each sexed group (dashed lines).

plausible model for explaining the variation in $F_{i j}$ included the influence of Management and Landscape Resistance (LR, wAIC $=1$, Table A1). Kinship between individuals within each management category was negatively correlated with LR (Fig. 4, Table A2). ED and Road Presence were less important for explaining kinship - although the values of resistance of the roads were also incorporated in the LR - while the null model presented the lowest wAIC value (wAIC $<0.001$, Table A1). When we calculated the mean kinship between individuals isolated and non-isolated by paved roads, the genetic kinship was greater between that individuals were not separated by roads (Fig. A4).

\section{Discussion}

We found negative micro-evolutionary consequences of forest fragmentation on the gene flow of the endangered GLT. Our results indicate that different land-cover types (forest, roads, pasture, and crops), as well as their spatial configuration and the distance between points, strongly affect the GLT dispersal at different degrees of landscape permeability. Even though distance was not the most plausible predictor in our models, it negatively influenced kinship between GLT individuals of both sexes. GLT could effectively disperse up to $8 \mathrm{~km}$, a value higher than what has been suggested from recapture data 
Table 1

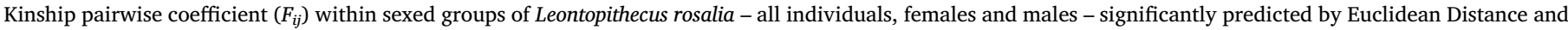

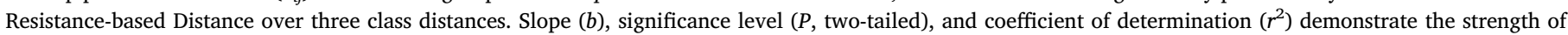
relationships.

\begin{tabular}{|c|c|c|c|c|c|c|c|c|c|}
\hline \multirow[t]{2}{*}{ Group } & \multirow[t]{2}{*}{ Extent of the spatial interval $(\mathrm{km})$} & \multicolumn{4}{|c|}{ Euclidean Distance (ED) } & \multicolumn{4}{|c|}{ Resistance-based Distance (RD) } \\
\hline & & $\mathrm{N}$ & $b$ & $r^{2}$ & $P$ & $\mathrm{~N}$ & $b$ & $r^{2}$ & $P$ \\
\hline \multirow[t]{3}{*}{ All individuals } & $0-10$ & 4465 & -0.02 & 0.16 & 0.00 & 4185 & -0.02 & 0.16 & 0.00 \\
\hline & $0-6$ & 3675 & -0.03 & 0.14 & 0.00 & 3089 & -0.03 & 0.14 & 0.00 \\
\hline & $0-2$ & 2166 & -0.03 & 0.03 & 0.00 & 1739 & -0.06 & 0.08 & 0.00 \\
\hline \multirow[t]{3}{*}{ Females } & $0-10$ & 822 & -0.02 & 0.12 & 0.00 & 760 & -0.02 & 0.13 & 0.00 \\
\hline & $0-6$ & 700 & -0.03 & 0.12 & 0.00 & 590 & -0.03 & 0.15 & 0.00 \\
\hline & $0-2$ & 422 & -0.03 & 0.02 & 0.00 & 341 & -0.06 & 0.08 & 0.00 \\
\hline \multirow[t]{3}{*}{ Males } & $0-10$ & 1419 & -0.02 & 0.19 & 0.00 & 1335 & -0.02 & 0.21 & 0.00 \\
\hline & $0-6$ & 1123 & -0.03 & 0.16 & 0.00 & 941 & -0.03 & 0.15 & 0.00 \\
\hline & $0-2$ & 649 & -0.04 & 0.04 & 0.00 & 527 & -0.64 & 0.09 & 0.00 \\
\hline
\end{tabular}

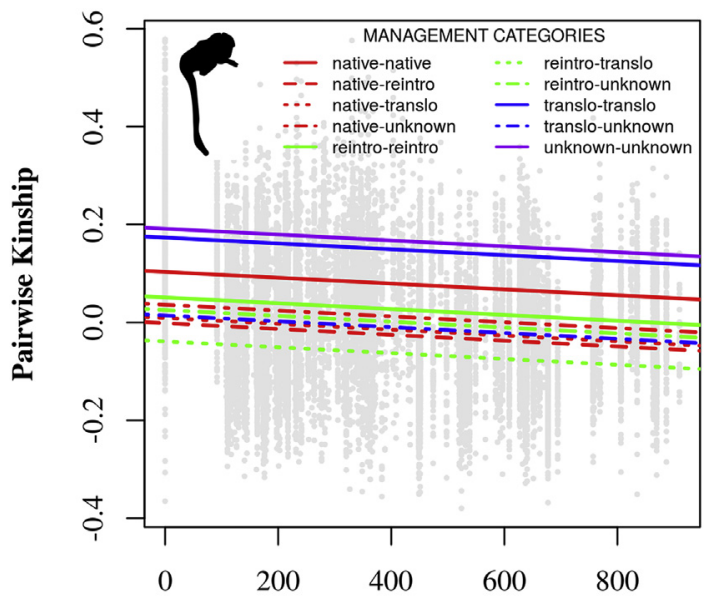

Landscape Resistance

Fig. 4. Effects of population management categories (Management: native, translocated, reintroduced, and unknown origin) and Landscape Resistance (LR) on genetic kinship variation observed between individuals of Leontopithecus rosalia within the Atlantic Forest.

(Mickelberg, 2011). A using study using spatially explicit agent-based simulations (Di Fiore and Valencia, 2014) showed that, when a barrier is added into the model, isolation by distance prevailed, but the barrier caused greater genetic differentiation on tamarins over time. Our findings corroborate this prediction; we found a pattern of isolation by resistance instead of isolation by distance only.

\subsection{Dispersal potential distances based on GLT genetics}

The distances at which we found shared alleles over time and global autocorrelation showed a positive but weak spatial genetic correlation at around $8 \mathrm{~km}$, and strong spatial genetic structure at around $2 \mathrm{~km}$. An isolation by distance pattern was observed around $15 \mathrm{~km}$, as expected when spatial scales are larger than the average dispersal distance of the species (Slatkin, 1985). Field research based on Euclidean Distance measures of recapture locations also estimated that most GLT movements were up to around $2 \mathrm{~km}$, and rarely beyond this distance, with a few GLTs traveling up to $6.6 \mathrm{~km}$ in a straight line (Mickelberg, 2011). Lampert et al. (2003) using molecular tools also found levels of genetic differentiation among populations of Physalaemus pustulosus at scales larger than those observed through the mark-recapture studies (Marsh et al., 1999, 2000). These results show that molecular tools can produce more robust results on dispersal patterns than estimates based exclusively on direct observation methods.

This higher kinship of GLTs around $2 \mathrm{~km}$ suggests a high gene flow within the limits of their own and adjacent groups home ranges (47-67 ha; Hankerson and Dietz, 2014). A similar pattern has been observed in a cooperatively breeding bird, Corcorax melanorhamphos (Beck et al., 2008), and in another primate species, Propithecus tattersalli (Quéméré et al., 2010). However, the positive autocorrelation of GLTs was also observed at a larger distance (around $8 \mathrm{~km}$ ) than the $1.5 \mathrm{~km}$ observed for $P$. tattersalli (Quéméré et al., 2010).

The Resistance-based Distance values that correlated with the positive kinship values were generally higher and accounted for more variation in the genetic kinship than the Euclidean Distance values. This result suggests that GLT dispersal distance increases proportionally with more landscape permeability. Therefore, we believe that GLTs could disperse long distances (up to $8 \mathrm{~km}$ ) more frequently if the landscape became sufficiently permeable. Dispersal over long distances may have had a positive effect on population persistence and genetic structure provided its frequency is above an effective threshold (Johst et al., 2002).

\subsection{Sex-unbiased effective dispersal}

In socially monogamous mammalian species, such as golden lion tamarins, both sexes disperse (Mabry et al., 2013). However, differences in breeding opportunities for males and females can lead to sexbiased dispersal. Molecular tools can contribute to measure the degree of sex-biased dispersal and its consequences on the gene flow, providing complementary information about demography and mating systems (Handley and Perrin, 2007; Prugnolle and de Meeus, 2002). We found similar spatial genetic structures for males and females, suggesting that there are no sex differences in effective dispersal (i.e., dispersal followed by reproduction). The absence of sex-biased dispersal has been observed in Leontopithecus caissara and another cooperatively breeding species, C. melanorhamphos (Beck et al., 2008; Martins et al., 2014). Long-term field studies of GLTs have reported a slight male-bias in the frequency of natal dispersal in both continuous and fragmented landscapes (Baker and Dietz, 1996; Paula, 2013). In fragmented landscapes, however, the breeding success after dispersal was not sex-biased in two species of lion tamarins (Paula, 2013; Raboy, 2002). The genetic results of this study support the interpretation that effective dispersal is not sex-biased.

Even if the frequency of dispersal is similar for both sexes, there may be sex differences in distance traveled (Douadi et al., 2007; McNutt, 1996; Norman and Spong, 2015). We found evidence suggesting sexdifferences in distance traveled: the distance decay curves differed slightly between males and females. Distance had slightly greater explanatory power for autocorrelation for males than for females particularly up to $10 \mathrm{~km}$. Thus, although the frequency of effective dispersal seems to be similar for males and females, males may be traveling longer distances. This should be tested in future studies.

The sex-unbiased effective dispersal is relevant to conservation 
because it maximizes gene flow and reduces the effects of the inherent reproductive skew of the monogamous cooperative mating systems. Conservation actions should promote ecological conditions that favor sex-unbiased effective dispersal by creating opportunities for movement into unoccupied fragments or fragments large enough to hold multiple territories and new reproductive groups. Sex differences in distance traveled may be important for population dynamics because one sex may contribute more to inter-population gene flow than the other.

\subsection{Population management and landscape resistance influence on GLT genetics}

As expected, the most important landscape variable for explaining the GLT dispersal was Landscape Resistance, which was present together with the variable Management in the most plausible model. This means that not only the distance between individuals matter for their kinship but also the composition of the landscape between them. The Resistance-based Distance (that corresponds to the distance of corridors that account for Landscape Resistance) appears to be a more realistic option than the Euclidean Distance for understanding how the organisms move through the landscape. Moreover, the human-mediated GLT dispersal events characteristic of conservation management also strongly affected the GLT genetic structure. Other primates are also threatened by forest discontinuity - e.g. Alouatta pigra (Pozo-Montuy et al., 2011), Saimiri oerstedii (Blair and Melnick, 2012), and Rhinopithecus bieti (Liu et al., 2009). Given the evidence so far, we recommend that the cost-distance relationship, which defines matrix permeability, be considered during the planning of management and conservation actions for arboreal animals.

Since Landscape Resistance was based on expert knowledge, understanding it in detail requires a closer look at the main land cover classes driving this result. Based on experts' opinion, pasture - the most prevalent land-cover class in the landscape $(\sim 60 \%)$ - had a moderate resistance (resistance $=55$, from a range of 1 to 100). In addition, due to intensive field observation by our experts, the highway BR-101 had the highest resistance (resistance $=100$ ) to GLT movement. The effect of roads was also verified by the genetic kinship between individuals isolated by paved roads, which was on average negative (see Fig. A4). The prevalence of these elements - pasture and roads - in hindering GLT movement must be taken into account in the implementation of landscape management and conservation actions. GLT dispersal may be possible through small distances over open areas (e.g. $\leq 100 \mathrm{~m}$; Mickelberg, 2011) as it is reported for other primate species - e.g. Alouatta palliata (Mandujano, 2005). For example, Coelho (2009) described an event of GLT dispersal across pasture using stepping stones between forest fragments. The enrichment of the pasture matrix with scattered trees or another spatial element - e.g. ecological corridors and stepping stones (Arroyo-Rodríguez and Mandujano, 2009; Mandujano et al., 2004) - should also facilitate inter-habitat movements. On the other hand, the roads with intense traffic such as the highway BR-101 should reduce gene flow without the implementation of measures to impede the barrier effect and maintain functional connectivity (e.g. Teixeira et al., 2013; Ciocheti et al., 2017).

\subsection{Implications for conservation}

Our results show that the negative effects of landscape discontinuity on the gene flow of wild populations may be occurring at a much faster pace than we are able to detect through field monitoring. Since the 1980s, the total number of GLT individuals in the wild has grown from approximately 400 (Coimbra-Filho and Mittermeier, 1977) to 3200 (AMLD, unpublished data) as a result of an intensive and long-term management of the populations (Holst et al., 2006; Kierulff et al., 2012). Despite this marked population growth, losses of genetic diversity of GLT were indeed detected over time (Moraes et al., 2017). These losses at the genetic level could occur rapidly and within a short time frame in arboreal species with closed social systems distributed in fragmented habitat (Di Fiore and Valencia, 2014). In addition to the social system and conservation management, landscape permeability is an important factor influencing GLT genetic structure across two to four generations. Thus, we advocate that maintaining more permeable landscapes is essential for guaranteeing effective dispersal and conservation of arboreal animals within fragmented landscapes.

We present four recommendations for the conservation of endangered species in fragmented landscapes: (1) to optimize conservation efforts, the extent to which conservation actions will be implemented should be based on the dispersal potential distance of the species; (2) movement and dispersal records of individuals between populations should be obtained, but in the absence of this data, expert knowledge may be used cautiously in the simulation of connectivity corridors; (3) open fields should be enriched with permeable landscape elements (e.g. scattered or continuous trees) to avoid arboreal animals being isolated in patches; and (4) conservation management (e.g. reintroduction and translocations) are immediate solutions to rescue populations threatened with extinction, however, they are not able to guarantee by themselves long-term population viability: it is paramount to restore functional connectivity of the landscape to maintain the interpopulation gene flow. Actions for forest restoration and increase of functional connectivity must also take into account the Landscape Resistance for the target species dispersal. We also suggest a careful evaluation of the effect of roads on dispersal, as well as empirical testing of measures that can minimize those effects on population size and gene flow among wild populations. The use of endangered species with great ecological restrictions (e.g. arboreal primates) to delimit these conservation actions may be a good strategy because it ensures that other less or equally demanding species are also conserved over time (Baguette et al., 2013; Lambeck, 2007).

Supplementary data to this article can be found online at https:// doi.org/10.1016/j.biocon.2018.05.023.

\section{Acknowledgments}

MCR received research grants from CNPq (312045/2013-1; 312292/2016-3). AMM and MCR were funded by PROCAD-CAPES (project \# 88881.068425/2014-01) and BBN by CAPES. MCR and RLM received financial support from FAPESP (2013/50421-2, 2015/177394). We thank M-King (native speaker), M-Cortês, A-Norman, MM-Vale and an anonymous reviewer for their comments on a previous version of the manuscript. We thank the AMLD, especially A-Martins, for providing the data and hair samples, the experts who participated in the interviews, and J-Assis for invaluable assistance. IACUC (University of Maryland) approved capture protocols.

\section{References}

Adriaensen, F., Chardon, J.P., Blust, G., Swinnen, E., Villalba, S., Gulinck, H., Matthysen, E., 2003. The application of "least-cost" modeling as a functional landscape model. Landsc. Urban Plan. 64, 233-247.

Akaike, H., 1974. A new look at the statistical model identification. IEEE Trans. Autom. Control 19, 716-723.

Amos, J.N., Bennett, A.F., Mac Nally, R., Newell, G., Pavlova, A., Radford, J.Q., Thomson, J.R., White, M., Sunnucks, P., 2012. Predicting landscape-genetic consequences of habitat loss, fragmentation and mobility for multiple species of woodland birds. PLoS One 7, e30888.

Amos, J.N., Harrison, K.A., Radford, J.Q., White, M., Newell, G., Nally, R.M., Sunnucks, P., Pavlova, A., 2014. Species- and sex-specific connectivity effects of habitat fragmentation in a suite of woodland birds. Ecology 95, 1556-1568.

Anderson, C.D., Epperson, B.K., Fortin, M.J., Holderegger, R., James, P.M.A., Rosenberg, M.S., Scribner, K.T., Spear, S., 2010. Considering spatial and temporal scale in landscape-genetic studies of gene flow. Mol. Ecol. 19, 3565-3575.

Arroyo-Rodríguez, V., Mandujano, S., 2009. Conceptualization and measurement of habitat fragmentation from the primates' perspective. Int. J. Primatol. 30, 497-514.

Baguette, M., Blanchet, S., Legrand, D., Stevens, V.M., Turlure, C., 2013. Individual dispersal, landscape connectivity and ecological networks. Biol. Rev. 88, 310-326.

Baker, A.J., Dietz, J.M., 1996. Immigration in wild groups of golden lion tamarins (Leontopithecus rosalia). Am. J. Primatol. 38, 47-56.

Beck, N.R., Peakall, R., Heinsohn, R., 2008. Social constraint and an absence of sex-biased 
dispersal drive fine-scale genetic structure in white-winged choughs. Mol. Ecol. 17, 4346-4358.

Bivand, R., Keitt, T., Rowlingson, B., 2016. rgdal: bindings for the geospatial data abstraction library. $\mathrm{r}$ Package version 1.1-10. https://CRAN.R-project.org/package= rgdal.

Blair, M.E., Melnick, D.J., 2012. Scale-dependent effects of a heterogeneous landscape on genetic differentiation in the Central American squirrel monkey (Saimiri oerstedii). PLoS One 7, 1-14.

Bonin, A., Bellemain, E., Eidesen, P.B., Pompanon, F., Brochmann, C., Taberlet, P., 2004. How to track and assess genotyping errors in population genetics studies. Mol. Ecol. $13,3261-3273$.

Burnham, K.P., Anderson, D.R., 2002. Model Selection and Multimodel Inference: A Practical Information-theoretic Approach, second ed. Springer-Verlag, New York, USA.

Castilho, C.S., Marins-Sá, L.G., Benedet, R.C., Freitas, T.O., 2011. Landscape genetics of mountain lions (Puma concolor) in southern Brazil. Mamm. Biol. 76, 476-483.

Ciocheti, G., De Assis, J.C., Ribeiro, J.W., Ribeiro, M.C., 2017. Highway widening and underpass effects on vertebrate road mortality. Biotropica 49, 765-769.

Coelho, A.S., 2009. Reintrodução do mico-leão-dourado, Leontopithecus rosalia, em fragmentos: sucesso reprodutivo, interações inter-grupais em corredores e conflito social ( $\mathrm{PhD}$ thesis). Universidade Estadual do Norte Fluminense.

Coimbra-Filho, A.F., Mittermeier, R.A., 1977. Conservation of the Brazilian lion tamarins Leontopithecus rosalia. In: HSH Prince Rainier III of Monaco, Bourne, G. (Eds.), Primate Conservation. Academic Press, London, pp. 59-94.

Dharmarajan, G., Beasley, J.C., Fike, J.A., Rhodes, O.E., 2014. Effects of landscape, demographic and behavioral factors on kin structure: testing ecological predictions in a mesopredator with high dispersal capability. Anim. Conserv. 17, 225-234.

Di Fiore, A., Valencia, L.M., 2014. The interplay of landscape features and social system on the genetic structure of a primate population: an agent-based simulation study using "tamarins". Int. J. Primatol. 35, 226-257.

Dietz, J.M., Baker, A.J., Miglioretti, D., 1994. Seasonal variation in reproduction, juvenile growth, and adult body mass in golden lion tamarins (Leontopithecus rosalia). Am. J. Primatol. 34, 115-132.

Dietz, J.M., Peres, C.A., Pinder, L., 1997. Foraging ecology and use of space in wild golden lion tamarins (Leontopithecus rosalia). Am. J. Primatol. 41, 289-305.

Douadi, M.I., Gatti, S., Levrero, F., Duhamel, G., Magdalena Bermejo, D.V., Menard, N., Petit, E.J., 2007. Sex-biased dispersal in western lowland gorillas (Gorilla gorilla gorilla). Mol. Ecol. 16, 2247-2259.

Estrada, A., Garber, P.A., Rylands, A.B., Roos, C., Fernandez-Duque, E., Di-Fiore, A., Nekaris, K.A., Nijman, V., Heymann, E.W., Lambert, J.E., et al., 2017. Impending extinction crisis of the world's primates: why primates matter. Sci. Adv. 3, 1-16.

Galbusera, P.H.A., Gillemot, S., 2008. Polymorphic microsatellite markers for the endangered golden-headed lion tamarin, Leontopithecus chrysomelas (Callitrichidae). Conserv. Genet. 9, 731-733.

Grativol, A.D., Ballou, J.D., Fleischer, R.C., 2001. Microsatellite variation within and among recently fragmented populations of golden lion tamarins (Leontopithecus rosalia). Conserv. Genet. 2, 1-9.

Graves, T.A., 2012. Spatial Ecology of Grizzly Bears in Northwestern Montana and Estimating Resistance to Gene Flow (PhD thesis). Northern Arizona University.

Hagell, S., Whipple, A.V., Chambers, C.L., 2013. Population genetic patterns among social groups of the endangered Central American spider monkey (Ateles geoffroyi) in a human-dominated landscape. Ecol. Evol. 3, 1388-1399.

Hall, L.A., Beissinger, S.R., 2014. A practical toolbox for design and analysis of landscape genetics studies. Landsc. Ecol. 29, 1487-1504.

Handley, L.J.L., Perrin, N., 2007. Advances in our understanding of mammalian sexbiased dispersal. Mol. Ecol. 16, 1559-1578.

Hankerson, S.J., Dietz, J.M., 2014. Predation rate and future reproductive potential ex plain home range size in golden lion tamarins. Anim. Behav. 96, 87-95.

Hardy, O.J., Vekemans, X., 2002. SPAGeDi: a versatile computer program to analyze spatial genetic structure at the individual or population levels. Mol. Ecol. Notes 2, 618-620.

Henriques-Silva, R., Frédéric, B., Calcagno, V., Urban, M.C., Peres-Neto, P.R., 2015. On the evolution of dispersal via heterogeneity in spatial connectivity. Proc. R. Soc. B 282, 20142879.

Hijmans, R.J., van-Etten, J., Cheng, J., et al., 2016. Package 'raster'. R package. https:// cran.r-project.org/web/packages/raster/index.html.

Holst, B., Medici, P., Marino-Filho, O.J., Kleiman, D., Leus, K., Vivekananda, G., Ballou, J., Traylor-Holzer, K., Raboy, B., Passos, F., et al., 2006. Lion Tamarin Population and Habitat Viability Assessment Workshop 2005, Final Report. IUCN/SSC Conservation Breeding Specialist Group, Apple Valley, MN, USA.

Johst, K., Brandl, R., Eber, S., 2002. Metapopulation persistence in dynamic landscapes: the role of dispersal distance. Oikos 98, 263-270.

Jones, O.R., Wang, J., 2012. A comparison of four methods for detecting weak genetic structure from marker data. Ecol. Evol. 2, 1048-1055.

Kierulff, M.C.M., Rylands, A.B., 2003. Census and distribution of the golden lion tamarin (Leontopithecus rosalia). Am. J. Primatol. 59, 29-44.

Kierulff, M.C.M., Rylands, A.B., Oliveira, M.M., 2008. Leontopithecus rosalia. In: The IUCN Red List of Threatened Species 2008: e T11506A3287321, http://dx.doi.org/10. 2305/IUCN.UK.2008.RLTS.T11506A3287321.

Kierulff, M.C.M., Ruiz-Miranda, C.R., Procópio-de-Oliveira, P., Beck, B.B., Martins, A., Dietz, J.M., Rambaldi, D.M., Baker, A.J., 2012. The Golden lion tamarin Leontopithecus rosalia: a conservation success story. Int. Zoo Yearb. 46, 36-45.

Lambeck, R.J., 2007. Focal species: a multi-species umbrella for nature conservation. Conserv. Biol. 11, 849-856.

Lampert, K.P., Rand, A.S., Mueller, U.G., Ryan, M.J., 2003. Fine-scale genetic pattern and evidence for sex-biased dispersal in the túngara frog, Physalaemus pustulosus. Mol.
Ecol. 12, 3325-3334.

Liu, Z., Ren, B., Wu, R., Zhao, L., Hao, Y., Wang, B., Wei, F., Long, Y., Li, M., 2009. The effect of landscape features on population genetic structure in Yunnan snub-nosed monkeys (Rhinopithecus bieti) implies an anthropogenic genetic discontinuity. Mol. Ecol. 18, 3831-3846.

Loiselle, B.A., Sork, V.L., Nason, J., Graham, C., 1995. Spatial genetic structure of a tropical understory shrub, Psychotria officinalis (Rubiaceae). Am. J. Bot. 82, 1420-1425.

Mabry, K.E., Shelley, E.L., Davis, K.E., Blumstein, D.T., Van Vuren, D.H., 2013. Social mating system and sex-biased dispersal in mammals and birds: a phylogenetic analysis. PLoS One 8, 1-9.

Mandujano, S., 2005. A metapopulation approach to conserving the howler monkey in a highly fragmented landscape in Los Tuxtlas, Mexico. In: Estrada, A., Garber, P.A., Pavelka, M.S.M., Luecke, L. (Eds.), New Perspectives in the Study of Mesoamerican Primates: Distribution, Ecology, Behavior, and Conservation. Springer, New York, pp. 513-538.

Mandujano, S., Escobedo-Morales, L.A., Palacios-Silva, R., 2004. Movements of Alouatta palliata among forest fragments in Los Tuxtlas, Mexico. Neotrop. Primates 12, $126-131$.

Marsh, D.M., Fegraus, E.H., Harrison, S., 1999. Effects of breeding pond isolation on the spatial and temporal dynamics of pond use by the tungara frog, Physalaemus pustulosus. J. Anim. Ecol. 68, 804-814.

Marsh, D.M., Rand, A.S., Ryan, M.J., 2000. Effects of inter-pond distance on the breeding ecology of tungara frogs. Oecologia 122, 505-513.

Martins, M.M., Nascimento, A.T.A., Nali, C., Velastin, G.O., Mangini, P.B., ValladaresPadua, C.B., Galetti Jr., P.M., 2014. A test for sex-biased dispersal in the black-faced lion tamarin (Leontopithecus caissara): inferences from microsatellite markers. Stud. Neotropical Fauna Environ. 50, 14-20.

McNutt, W.J., 1996. Sex-biased dispersal in African wild dogs, Lycaon pictus. Anim. Behav. 52, 1067-1077.

McRae, B.H., 2006. Isolation by resistance. Evolution 60, 1551-1561.

Mickelberg, J.L., 2011. Understanding and Managing Isolation in a Fragmented Population of Golden Lion Tamarins, Leontopithecus rosalia (PhD thesis). George Mason University.

Moraes, A.M., Ruiz-Miranda, C.R., Ribeiro, M.C., Grativol, A.D., Carvalho, C.D.S., Dietz, J.M., Kierulff, M.C.M., Freitas, L.A., Galetti Jr., P.M., 2017. Temporal genetic dynamics of reintroduced and translocated populations of the endangered golden lion tamarin (Leontopithecus rosalia). Conserv. Genet. 18, 995-1009.

Nathan, R., 2008. An emerging movement ecology paradigm. PNAS 105, 19050-19051.

Neteler, M., Bowman, H.M., Landa, M., Metz, M., 2012. GRASS GIS: a multi-purpose open source GIS. Environ. Model. Softw. 31, 124-130.

Norman, A.J., Spong, G., 2015. Single nucleotide polymorphism-based dispersal estimates using noninvasive sampling. Ecol. Evol. 5, 3056-3065.

Oklander, L.I., Kowalewski, M.M., Corach, D., 2010. Genetic consequences of habitat fragmentation in black-and-gold howler (Alouatta caraya) populations from northern Argentina. Int. J. Primatol. 31, 813-832.

Paula, V.R., 2013. Comportamento de dispersão dos micos-leões-dourados (Leontopithecus rosalia, Linnaeus, 1766) reintroduzidos e seus descendentes nascidos em vida livre (Academic Dissertation). Universidade Estadual do Norte Fluminense.

Perez-Sweeney, B.M., Valladares-Padua, C., Burrell, A.S., Di Fiore, A., Satkoski, J., Groot, P.J.V.C., Boag, P.T., Melnick, D.J., 2005. Dinucleotide microsatellite primers designed for a critically endangered primate, the black lion tamarin (Leontopithecus chrysopygus). Mol. Ecol. Notes 5, 198-201.

Pozo-Montuy, G., Serio-Silva, J.C., Bonilla-Sánchez, Y.M., 2011. Influence of the landscape matrix on the abundance of arboreal primates in fragmented landscapes. Primates 52, 139-147.

Procópio-de-Oliveira, P., Grativol, A., Ruiz-Miranda, C., 2008. Conservação do mico-leãodourado: enfrentando os desafios de uma paisagem fragmentada. Universidade Estadual do Norte Fluminense Darcy Ribeiro Press, Campos dos Goytacazes-RJ, Brazil.

Prugnolle, F., de Meeus, T., 2002. Inferring sex-biased dispersal from population genetic tools: a review. Heredity $88,161-165$.

Quéméré, E., Crouau-Roy, B., Rabarivola, C., Louis, E.E., Chikhi, L., 2010. Landscape genetics of an endangered lemur (Propithecus tattersalli) within its entire fragmented range. Mol. Ecol. 19, 1606-1621.

R Core Team, 2016. R: A Language and Environment for Statistical Computing. R Foundation for Statistical Computing, Vienna, Austria. https://www.R-project.org/.

Raboy, B.E., 2002. The Ecology and Behavior of Wild Golden-headed Lion Tamarins (Leontopithecus chrysomelas) (PhD thesis). University of Maryland.

Raboy, B.E., Dietz, J.M., 2004. Diet, foraging, and use of space in wild golden-headed lion tamarins. Am. J. Primatol. 63, 1-15.

Ribeiro, M.C., Metzger, J.P., Martensen, A.C., Ponzoni, F.J., Hirota, M.M., 2009. The Brazilian Atlantic Forest: how much is left, and how is the remaining forest distributed? Implications for conservation. Biol. Conserv. 142, 1141-1153.

Ribeiro, J.W., Santos, J.S., Dodonov, P., Martello, F., Niebuhr, B.B.S., Ribeiro, M.C., 2017. Landscape Corridors (LSCorridors): a new software package for modeling ecological corridors based on landscape patterns and species requirements. Methods Ecol. Evol. 8, 1425-1432.

Row, J.R., Blouin-Demers, G., Lougheed, S.C., 2010. Habitat distribution influences dispersal and fine-scale genetic population structure of eastern foxsnakes (Mintonius gloydi) across a fragmented landscape. Mol. Ecol. 19, 5157-5171.

Ruiz-Miranda, C., Beck, B., Kleiman, D., Martins, A., Dietz, J., Rambaldi, D.M., Kierulff, M.C., Oliveira-Procopio, P., Baker, A., 2010. Re-introduction and translocation of golden lion tamarins, Atlantic Coastal Forest, Brazil: the creation of a metapopulation. In: Soorae, P.S. (Ed.), Global Re-introduction Perspectives: 2010. IUCN/SSC Reintroduction Specialist Group, UAE, pp. 225-230. 
Santos, J.S., 2014. Influência da pemeabilidade da matriz e heterogeneidade da paisagem na conservação da biodiversidade de mamíferos terrestres (PhD thesis). Instituto Nacional de Pesquisas Espaciais.

Seabra, V.S., 2012. Análise da paisagem em apoio aos estudos de favorabilidade à recuperação florestal na bacia hidrográfica do Rio São João (PhD thesis). Universidade Federal do Rio de Janeiro.

Shirk, A.J., Wallin, D.O., Cushman, S.A., Rice, C.G., Warheit, K.I., 2010. Inferring land scape effects on gene flow: a new model selection framework. Mol. Ecol. 19, 3603-3619.

Silva, L.G., Ribeiro, M.C., Hasui, E., Costa, C.A., da Cunha, R.G.T., 2015. Patch size, functional isolation, visibility and matrix permeability influences neotropical primate occurrence within highly fragmented landscapes. PLoS One 10, 1-20.

Slatkin, M., 1985. Gene flow in natural populations. Annu. Rev. Ecol. Syst. 16, 393-430. Soare, T.W., Kumar, A., Naish, K.A., O'Donnell, S., 2014. Genetic evidence for landscape effects on dispersal in the army ant Eciton burchellii. Mol. Ecol. 23, 96-109.

Sork, V.L., Waits, L., 2010. Contributions of landscape genetics-approaches, insights, and future potential. Mol. Ecol. 19, 3489-3495.

Spear, S.F., Balkenhol, N., Fortin, M.J., McRae, B.H., Scribner, K., 2010. Use of resistance surfaces for landscape genetic studies: considerations for parameterization and analysis. Mol. Ecol. 19, 3576-3591.

Storfer, A., Murphy, M.A., Evans, J.S., Goldberg, C.S., Robinson, S., Spear, S.F., Dezzani, R., Delmelle, E., Vierling, L., Waits, L.P., 2007. Putting the "landscape" in landscape genetics. Heredity 98, 128-142.

Taylor, P.D., Fahrig, L., Henein, K., Merriam, G., 1993. Connectivity is a vital element of landscape structure. Oikos 68, 571-573.

Teixeira, F.Z., Printes, R.C., Fagundes, J.C.G., Alonso, A.C., Kindel, A., 2013. Canopy bridges as road overpasses for wildlife in urban fragmented landscapes. Biota Neotrop. 13, 117-123.

Vekemans, X., Hardy, O.J., 2004. New insights from fine-scale spatial genetic structure analyses in plant populations. Mol. Ecol. 13, 921-935.

Zalewski, A., Piertney, S.B., Zalewska, H., Lambin, X., 2009. Landscape barriers reduce gene flow in an invasive carnivore: geographical and local genetic structure of American mink in Scotland. Mol. Ecol. 18, 1601-1615.

Zurr, A.F., Ieno, E.N., Walker, N.J., Saveliev, A.A., Smith, G.M., 2009. Mixed effects models and extensions in ecology with r. J. Chem. Inf. Model. 32 (574 pp.). 